\title{
Cross-Sectional Analysis of Cognitive And Functional Difficulties Among Adolescents Living With HIV In Low- Resourced Settings: Can A Simple Screening Algorithm Identify Adolescents For Support?
}

Helen Natukunda ( $\nabla$ helenpretty75@yahoo.com )

Makerere University College of Humanities and Social Sciences https://orcid.org/0000-0001-8958-9138

Elona Toska

University of Cape Town

Mark Boyes

Curtin University

Lorraine Sherr

University College London

Jaqueline Hoare

University of Cape Town

Sam Nightingale

University of Cape Town

Lucie D Cluver

University of Oxford

Research article

Keywords: Algorithm, HIV, Cognitive and functional

Posted Date: September 25th, 2020

DOI: https://doi.org/10.21203/rs.3.rs-71577/v1

License: (c) (i) This work is licensed under a Creative Commons Attribution 4.0 International License. Read Full License 


\section{Abstract}

Background: Comprehensive neuropsychological testing for adolescents living with HIV is rare and often impractical for overstretched healthcare systems in low-resourced settings. This study aimed to 1) test the potential of a simple algorithm to screen for cognitive and functional difficulties among at-risk adolescents, and 2) using this algorithm, investigate the correlates of cognitive and functional difficulties in a large community-traced sample of South African adolescents.

Methods: The study interviewed 10-19-year-old adolescents living with HIV ( $\mathrm{n}=1059$ ) and uninfected community controls ( $n=467)$, attending 53 public health facilities in the Eastern Cape in 2014-15. Cognitive and functional difficulties were assessed using an algorithm (either adolescent reports of memory, attention or concentration problems, or $<60 \%$ total recall on a memory task, or caregiver reports of an adolescent being a 'slow-learner', or attending a special needs school) and adolescent reports of functional difficulties. Data on healthcare and psychosocial variables were also collected. Multivariable logistic regressions tested correlates of cognitive and functional difficulties, controlling for sociodemographic and household covariates.

Results: Across the sample, the prevalence of cognitive and functional difficulties was 19.3\% (95\% Cl: 17.4-21.4). Adolescents living with HIV had significantly higher rates of cognitive and functional difficulties than community controls (21.9\% vs. $13.5 \%, p<.001)$. Validating the algorithm with self-reported school grade repetition (lifetime) and number of grades repeated, cognitive and functional difficulties were associated with higher odds of lifetime grade repetition (aOR1.62 95\% Cl 1.24-2.11) and a higher likelihood of repeating multiple grades $(\beta=0.27, p<.001)$.

Independent of covariates, potential correlates of cognitive and functional difficulties among adolescents were higher depressive symptoms (aOR1.18 95\%Cl1.11-1.26), concurrent infections (aOR1.92 95\%Cl1.44-2.58), and more often missing school for clinic appointments (aOR1.66 95\%Cl1.24-2.23).

Conclusions: Cognitive and functional difficulties were more prevalent among adolescents living with HIV than community controls and were associated with psychosocial, physical health, and healthcare factors. Simple algorithms - like the one tested in this study - may be feasible for use in low-resourced settings, following validation against neuropsychological assessment batteries in specialised facilities. Routine screening for cognitive and functional difficulties may be integrated into HIV care to identify adolescents for additional support.

\section{Introduction}

Cognitive deficits may directly affect adolescents' ability to reach their full potential, especially in resource-limited settings. Global rates of cognitive difficulties among adolescents living with HIV (ALHIV) range from $17 \%$ in highincome countries (1) to $45 \%$ in low-income settings (2). Children in Sub-Saharan Africa are at a greater risk of neurocognitive impairment potentially associated with widespread poverty, malnutrition, and endemic malarial infections including cerebral malaria whose effects on brain functioning tend to persist (3). ALHIV may be at an even greater risk of cognitive challenges potentially resulting from exposure of the developing brain to maternal HIV or antiretroviral therapy (ART) in the womb $(4,5)$, the direct effects of own vertically-acquired HIV infection $(6,7)$, ongoing HIV-associated inflammatory responses $(8,9)$, and HIV-associated opportunistic infections (10).

Depending on the timing of infection, adolescents who are infected during adolescence (horizontally-infected) may have different trajectories of cognitive effects compared with those infected in utero or postnatally during childbirth and breast feeding (vertically-infected). Vertically-infected adolescents have lived longer with HIV including infection during critical stages of neurodevelopment and are likely to have more cognitive challenges than horizontally-infected adolescents. From a neuroprotective perspective of combination antiretroviral therapy (cART), they have also had the 
longest exposure to effective treatment and are expected to have fewer cognitive challenges than horizontally-infected adolescents. Conversely, from the theory of CART neurotoxicity and assumption of viral suppression, vertically-infected adolescents may have worse challenges than horizontally-infected adolescents due to longer cART exposure periods but this is not always true. Systematic reviews show that children in resource-constrained settings do not start treatment as fast as they should and do not always achieve persistent viral suppression due to several contextual factors including suboptimal access and retention in care (11). Our understanding of either theory is limited by failure of current ALHIV studies to disaggregate findings by mode of infection $(10,12)$ or the narrow focus on verticallyinfected adolescents (13).

Cognitive deficits have been linked with difficulties in activities of daily living (14), sub-optimal adherence to cART (14, 15), and poorer educational outcomes among youth living with HIV (16). Cognitive difficulties may also play a role in the complex skills needed to avoid risky behaviour, such as negotiating safety, self-confidence to avoid drug and alcohol misuse, and strategic planning and coping to navigate social challenges. However, cognitive functioning of ALHIV in Sub-Saharan Africa remains a neglected area of research and service provision $(17,18)$. This is compounded by the limited availability of resources (both technical and financial) required to administer comprehensive neuropsychological assessment batteries to identify functioning levels and refer to services where available. Consequently, data in this age group remain sparse several decades into the global HIV response, limiting our understanding of the rates and correlates of cognitive deficits among ALHIV in the region.

Notably, not all ALHIV perform poorly on neuropsychological assessment tests. This then begs the question, what are the risk and protective correlates for neurocognitive impairment among ALHIV? Some cross-sectional studies report HIV-related measures (higher plasma viral load and lower CD4 count) (19-21) as risk factors for neurocognitive impairment among ALHIV while others report non HIV-related risk factors such as caregiver unemployment, poor nutrition, and orphanhood (22), and higher depression scores may be important to consider (13). Moreover, high rates of psychological $(23-26)$ and psychiatric disorders $(27,28)$ have been reported among adolescents in Sub-Saharan Africa, and depression has been shown to be reciprocally associated with cognitive functioning in the general population (29). Cognitive abilities are known to vary with age, with better performance seen among younger than older individuals. Gender disparity in cognitive ability is a controversial topic. Findings from studies that have examined this relationship show sex differences in adolescent cognitive abilities in the general population, with girls tending to outperform boys on memory tasks whereas boys exhibited stronger visuo-spatial cognitive performance than girls (30). These findings were supported by a brainmap metanalysis using activation likelihood estimation (31). Although sex differences in cognitive functioning are consistently reported, systematic reviews show that these differences are not large enough for establishment of sexual dimorphism due to a large degree of sexual overlap in the cognitively normal category (11). In contrast, some studies report no sex differences in performance on most cognitive tasks among adults living with HIV (32) except for tasks assessing motor and psychomotor difficulties, where young women were shown to have more problems than young men (33). Whether these HIV by sex interaction patterns are true for ALHIV is unclear and warrant further investigation.

Understanding the burden, risk and protective factors for cognitive dysfunction among ALHIV in low-resourced settings is crucial for the development of targeted context-appropriate interventions to help young people living with HIV reach their full potential, and has implications for prevention of onwards HIV transmission in this unique age group. This cross-sectional study explored the use of an algorithm of easily obtainable measures to assess the extent of and factors associated with cognitive and functional difficulties in a large community-traced sample of ALHIV and uninfected controls in South Africa. It also explored age and sex patterns in cognitive and functional difficulties and tested for moderation. The study objectives were: 
1. Explore the utility of an algorithm of easily obtained measures to code for cognitive and functional difficulties including adolescent self-report, caregiver report, and objective observer administered memory tests as an indicator of difficulties.

2. Estimate the prevalence of cognitive and functional difficulties assessed using the algorithm among South African adolescents differentiated by age, sex, HIV status and mode of HIV infection.

3. Describe the correlates of cognitive and functional difficulties among ALHIV and community controls in South Africa, and test whether sex moderates the effect of HIV on cognitive and functional difficulties.

\section{Methods}

All public health facilities providing HIV services in Amanthole District, Eastern Cape Province were invited to participate in the study in 2014-2015 ( $n=53$ facilities at baseline). Ethical clearance was provided by the University of Oxford (SSD/CUREC2/12-21), the University of Cape Town (CSSR 2013/4; 2019/01), South African Departments of Health (29/08/2014) and Basic Education (04/04/2014), and all participating health facilities. All 10-19-year-old ARTinitiated adolescents in participating public health facilities were identified ( $n=1175$ eligible) and followed up in their homes (community tracing) to enable participant inclusion regardless of clinic attendance status (active or lost to follow-up). Reasons for non-participation were caregiver or adolescent refusal (4.1\%), severe cognitive delay (0.9\%), untraceable (3.7\%) and not interviewed for safety reasons (1.2\%). Tools were adapted in consultation with our youth advisory group and local stakeholders, were translated and back-translated from English to Xhosa and piloted with ALHIV $(n=25)$. Quantitative interviews were conducted with $n=1059$ ART-initiated adolescents $(90.1 \%$ of the eligible sample) by a local team of interviewers who were trained in the ethics of research involving children and adolescents. Adolescents aged $\geq 18$ years provided full consent to participate in the study whereas younger adolescents assented with their caregivers providing full consent. To prevent the potential stigmatising effects of HIV/AIDS research, the study was generally presented as assessing adolescent healthcare needs. Consequently, 10-19-year-old apparently HIV-negative adolescents who were either living in the same home or a neighbouring home were also interviewed. HIV status was ascertained using a sequential elimination process (34). Firstly, we searched patient files and Tier.net records in all participating health facilities. Adolescents were identified as living with HIV if their file or record indicated that they had tested positive for HIV. Secondly, adolescents with no clinical HIV record were screened using an adapted symptoms- and healthcare-seeking checklist that has been widely used in Sub-Saharan Africa to track undiagnosed HIV/AIDS-related cases $(35,36)$. Lastly, adolescents were classed as 'community controls' if they did not report or have an HIV-positive clinical record at any facility, had never been on ART/ long-term medication, or did not meet the HIV symptoms criteria. Details of this research have been previously described (37-39).

\section{Measures}

Where available, measures used items from validated scales that have been widely used in Sub-Saharan Africa. Internal validity (alpha) values for the whole sample in the current study are presented throughout where relevant.

Cognitive and functional difficulties assessment used a combination of measures: First, adolescent reports of difficulty remembering things or following a story or conversation in the past 6 months, were assessed using one item from the UNICEF child functioning module, (40) scored on a 4-point Likert scale (no difficulty, some difficulty, a lot of difficulty, cannot do it at all). The scale was dichotomised into no cognitive problems/cognitive problems. Second, attention and concentration problems were assessed using 2 items from the attention deficit hyperactivity disorder subscale of the Strengths and Difficulties Questionnaire (SDQ) (41) e.g. I am easily distracted - I find it hard to concentrate (not true for me, somewhat true for me, certainly true for me). The SDQ has been widely used in studies of orphans and 
vulnerable children in Sub-Saharan Africa (42) including among those affected by HIV $(34,43)$ (current study full scale $a=0.52$ ). Third, a memory task testing recall of 5 context-appropriate words (apple, red, car, ball, and hope) was adapted from the WISC-IV cognitive assessment tool (44). The WISC-IV tool has previously been used to assess cognitive performance among South African children (45). Adolescents were given a trial to ensure comprehension prior to task completion. The words were spoken aloud one at a time by trained interviewers, in the same sequence. Adolescents were asked to repeat verbally the 5 words in the order they had heard them during the test, immediately after presentation of all the 5 words (immediate recall) and later after completing another unrelated task (delayed recall). Adolescent responses were entered in the tablet by the interviewer. During data cleaning, each word correctly remembered was awarded a score of 1 . A scale of correctly recalled words at each assessment timepoint was generated by summing up individual scores for each word (range: $0-5)$. Total (global) recall was a summation of the immediate and delayed recall scores (range: 0-10). Owing to the lack of published age and context-relevant cut-offs for the WISC-IV word recall subset, sub-optimal performance on the memory task was operationalised as scoring $<6$ out of 10 points on the global recall scale $(<60 \%)$. This captured the bottom $63 \%$ in terms of performance score distribution. Fourth, additional cognitive information such as the adolescent being a "slow-learner" (one caregiverreported item) or attending a special needs school was obtained from caregiver and school reflection forms (caregiverreported items). Fifth, adolescent reports of functional difficulties (difficulties in activities of daily living) used one item from the UNICEF module of child functioning, (40) asking if adolescents had experienced difficulty seeing, hearing, walking or climbing steps, washing themselves or getting dressed (past 6 months), scored on a 4-point Likert scale (no difficulty to cannot do at all). The scale was dichotomised such that $0=$ no functional difficulties and $1=$ any difficulties (scores $\geq 1$ ).

A brief screening tool for assessing cognitive and functional difficulties comprised of 7 items and was assembled using the following algorithm to create a binary outcome: (Either adolescent reports of past 6-month difficulty remembering things, following a story or conversation 'OR' SDQ attention problems (any) 'OR' SDQ concentration problems (any) 'OR' < 60\% total recall on a memory task 'OR' caregiver reports of an adolescent being a 'slow-learner' 'OR' attending a special needs school) 'AND' adolescent reports of past 6-month functional difficulties. In summary, cognitive difficulties $=$ any cognitive problems + functional problems. The algorithm was validated using 2 measures: adolescent reports of lifetime grade repetition and lifetime number of repeated grades.

Potential correlates for cognitive and functional difficulties among ALHIV in the current literature were identified and grouped into 2 categories shown below.

Psychosocial factors included measurement of six psychosocial variables. Adolescent depressive symptoms, assessed using a condensed version of the Child Depression Inventory (10 items, $a=0.63$ ) previously used in South Africa (46). Scores ranged from 0-18, higher scores reflected worse depressive symptoms. Post-traumatic stress disorder (PTSD) symptoms were assessed using 19 items of the Child PTSD Checklist (47) previously validated using a sample of AIDS-affected children (48) $(a=0.90)$. Suicidality assessment used the suicidality and self-harm subscale of the Mini International Neuropsychiatric Interview for Children and Adolescents - MINI-Kid (49) (5 items, $a=0.87$ ). Substance abuse assessment used one item from the WHO-AUDIT scale (50), asking adolescents about past 3-month hazardous alcohol and drug use. HIV-associated internalised stigma used 6 items from the ALHIV-SS scale $(a=0.72)$ previously culturally-adapted using the current sample (51).

Healthcare-related factors were missing school for clinic appointments (adolescent-reported), assessed using a single item adapted from the PREPARE trial (52), scored on a 4-point Likert scale $(0=$ never, $1=$ once or twice, $2=$ several times, 3 = most of the time). The scale was dichotomised into less often missing school (never/once or twice $=0)$ and more often missing school for clinic appointments (several times/most of the time $=1$ ). Concurrent infections were 
assessed using a verbal symptoms scale $(35,36)$ and dichotomised as past 6-month reports of skin rash/shingles, or sores on the body or face, or mouth ulcers, or symptomatic tuberculosis (TB). Probable TB assessment used an algorithm of suggestive clinical symptoms (any chronic cough 'AND' (any yellow/green 'OR' any bloody sputum)) 'AND' scoring 2 or more on the weight loss scale 'AND' any night sweats 'AND' any fever 'AND' any chest pains $(53,54)$. cART duration was calculated as the difference between adolescent age and age at ART initiation. Vertical HIV infection was defined as having initiated ART before 12 years of age or CART duration $>5$ years (55). Non-adherence was defined as $<95 \%$ medication doses taken as prescribed in the past week (56), assessed by adolescent self-report based on items from the standardised Patient Medication Adherence Questionnaire (57), combined with measures developed in Botswana for adolescent past-week, past-3 days and past-weekend adherence (58). Adolescent reports of past-week ART non-adherence in this study were validated using viral load data and self-reported opportunistic infections in prior analyses (37).

Potential confounders included: 1) sociodemographic factors of adolescent age, sex, rural residence, informal housing (e.g. living in a shack or hut made of traditional material), school grade, and orphanhood (losing at least one parent), all assessed by self-report. 2) Household factors were poverty, assessed as lacking access to all the 8 sociallyperceived necessities i.e. books, fees, uniform, shoes, enough clothing and a blanket to keep warm, 2 meals a day, and visiting the doctor when sick (59), and food insecurity (at least 2 days in the past week without enough food in the home) (39).

\section{Analysis Strategy}

Data analysis was conducted in stages in Stata 14/IC. First, adolescents living with HIV were compared with community controls on a range of characteristics. Second, to validate the proposed algorithm, logistic and negative binomial regressions tested associations of cognitive and functional difficulties with reports of lifetime grade repetition (binary) and lifetime number of grades repeated (skewed count data) respectively, simultaneously controlling for sociodemographic and household factors, HIV status and missing school for clinic appointments. Third, rates of cognitive and functional difficulties disaggregated by age, sex, HIV status and mode of HIV infection were computed using cross-tabulations, compared using a series of Chi-squared tests and graphically presented. Fourth, psychosocial and healthcare-related correlates of cognitive and functional difficulties were simultaneously tested in multivariable logistic regression models controlling for sociodemographic and household covariates. Mode of HIV infection and CART duration were dropped from multivariable analyses owing to significant collinearity with age and HIV status, indicated by variance inflation factors $>10$. To test whether sex moderated the relationship between HIV and cognitive and functional difficulties, and interpret the findings, we fitted an HIV by sex interaction term in the regression model and computed the adjusted predicted probability of reporting cognitive and functional difficulties using marginal effects modelling.

\section{Results}

\section{Characteristics of adolescents in the study sample}

In the full sample, median age was 14 (interquartile range (IQR): $11-17$ ), $57 \%$ girls, $22 \%$ rural residence, $18 \%$ informal dwellings, $66 \%$ lacked all the basic necessities, $14 \%$ were food insecure in the past week, and over half (52\%) were orphans (Table 1). School enrolment was $94 \%$. Of these, $55 \%$ were in primary school, $85 \%$ of whom were in ageappropriate grade. Compared with community controls, ALHIV were significantly younger (median age 13 years vs. 15 years, $p<.001)$, fewer girls ( $55 \%$ vs. $61 \%, p=.036)$, less likely to be in an age-appropriate grade $(46 \%$ vs. $57 \%, p<.001)$, more likely to have repeated a grade (50.0\% vs. $42.2 \%, p=.005)$, with more ALHIV reporting having lost at least one 
parent $(59 \%$ vs. $37 \%, p<.001)$. Substance abuse was lower among ALHIV than community controls (3.8\% vs. $6.4 \%$, $p=.023)$. Significantly more ALHIV reported concurrent infections $(63.6 \%$ vs. $43.9 \%, p<.001)$ and more often missed school for clinic appointments (35.2\% vs. $7.3 \%, p<.001)$. However, depressive symptoms, PTSD, and suicidality did not differ by HIV status. Among ALHIV ( $\mathrm{n}=1059)$, the mean HIV-related internalised stigma was 0.59 (SD: 1.29), median treatment duration was 5 years (IQR: 2-10), and past-week non-adherence was $36.4 \%$ (Table 1).

\section{Cognitive and functional difficulties among adolescents, by sex, HIV status and mode of HIV infection}

For adolescent-reported cognitive items, past 6-month reports of cognitive difficulties did not differ by sex. ALHIV were more likely to report past 6-month cognitive difficulties than community controls, 30.4\% vs. 19.1\%, $p<.001$ (Table 1). Past 6-month reports of cognitive difficulties did not differ by mode of HIV infection (horizontal/vertical). SDQ attention and concentration measures did not differ by sex or HIV status or mode of infection. Caregiver/school reports of "slow-learner" and special school attendance did not differ by HIV status. For the objective memory task (total recall), a higher proportion of boys than girls scored $<60 \%$, although this was not significant $(64.2 \%$ vs. $59.6 \%, p=.070)$. A similar non-significant trend was observed among ALHIV (64.1\% vs. 59.7\%, $p=.144)$. Performance on the memory task did not differ by HIV status or mode of HIV infection. Past 6-month adolescent reports of functional difficulties did not differ by sex. ALHIV were more likely to report past 6-month functional difficulties than community controls $(24.4 \%$ vs. $15.9 \%, p<.001)$. However, past 6 -month reports of functional difficulties did not significantly differ by mode of HIV infection (horizontal/vertical). Using our screening algorithm for total cognitive and functional difficulties, ALHIV had higher rates of combined cognitive and functional difficulties compared with community controls, $21.9 \%$ vs. $13.5 \%$, $p<.001$, respectively (Table 1$)$.

\section{Validating cognitive and functional difficulties assessed using the algorithm}

Findings from regression analyses showed that cognitive and functional difficulties assessed using the proposed algorithm were associated with higher odds of repeating a school grade (aOR = 1.62, Cl: 1.24-2.11, $p<.001)$ and a higher likelihood of repeating many grades $(\beta=0.27$, Cl: $0.11-0.43, p<.001)$, independent of age, sex, rural residence, informal housing and orphanhood, poverty, food insecurity, HIV status and missing school for clinic appointments (Table 2).

Cognitive and functional difficulties among adolescents by age and HIV status

In age-stratified analyses, our findings show that cognitive and functional difficulties were significantly more prevalent among ALHIV than community controls, within both the younger and older age groups (Fig 1).

Cognitive and functional difficulties among adolescents, by sex and HIV status

Sex appeared to moderate the relationship between HIV status and cognitive and functional difficulties among adolescents, with the risk difference between ALHIV and community controls being large and significant for boys (ALHIV vs. community controls: $22.1 \%$ vs. $8.7 \%, \chi^{2}=15.64, p<.001$ ) but not significant for girls (ALHIV vs. community controls: $21.8 \%$ vs. $16.6 \%, \chi^{2}=3.26, p=.071$, Fig 2 ). These findings were tested by fitting the HIV status by sex interaction term in multivariate logistic regression models (Table 3 ).

Cognitive and functional difficulties among adolescents by age, HIV status, and mode of infection 
Our findings show that rates of cognitive and functional difficulties were not significantly different for younger and older adolescents among horizontally-infected and vertically-infected ALHIV, and community controls (Fig 3).

\section{Cognitive and functional difficulties among adolescents by sex, HIV status and mode of infection}

Cognitive and functional difficulties did not differ by sex among ALHIV (boy vs. girl: $22.1 \%$ vs. $21.8 \%$ ). Additionally, no significant sex differences in cognitive and functional difficulties were observed among both horizontally-infected and vertically-infected adolescents (Fig 4). However, for community controls, rates of cognitive and functional difficulties were significantly higher among girls than boys ( $16.6 \%$ vs. $8.7 \%, p=.016$, Fig 4).

\section{Multivariable regression analysis of psychosocial and healthcare-related correlates of cognitive and functional} difficulties, HIV by sex interaction and potential confounders

Independent of covariates, psychosocial and healthcare-related correlates of cognitive and functional difficulties were higher depressive symptoms (aOR per unit increase $=1.18, \mathrm{Cl}$ : 1.11-1.27, $p<.001$ ), more often missing school for clinic appointments (aOR = 1.66, Cl: 1.24-2.23, $p<.001)$, and concurrent infections (aOR = 1.92, Cl: 1.44-2.58, $p<.001)$. The HIV $x$ sex interaction term was significant $(\mathrm{aOR}=2.04, \mathrm{Cl}: 1.02-4.07, p<.05)$ (Table 3). Findings from modelling the adjusted predicted probabilities showed that ALHIV boys were significantly more likely to report cognitive and functional difficulties than HIV-negative boys: $20.8 \%$ and $11.1 \%$ respectively; whereas the probability of reporting cognitive and functional difficulties did not differ significantly by HIV-status among adolescent girls: $20.4 \%$ and $19.2 \%$ among ALHIV girls and HIV-negative girls respectively (Fig 5).

\section{Discussion}

The study aimed to explore the potential of a brief screening algorithm for cognitive and functional difficulties, describe patterns by age, sex, HIV status and mode of HIV infection, and correlates of difficulties among adolescents. Overall, more than a quarter (26.9\%) of adolescents in our study reported past 6-month cognitive difficulties. About 1 in $5(21.8 \%)$ reported past 6-month functional difficulties (difficulties in activities of daily living). More than 3 in5 (61.6\%) scored $<60 \%$ on the memory test. Based on the proposed screening algorithm (which captured subjective attention, concentration, subjective and objective memory, and subjective functioning measures), about 1 in 5 (19.3\%) of the adolescents in our community-traced sample were classed as having cognitive and functional difficulties. Rates of cognitive and functional difficulties assessed using the algorithm were high among both ALHIV and community controls but significantly higher for ALHIV i.e. more than 1 in 5 (21.9\%) and 1 in 8 (13.5\%) respectively. These findings are consistent with those from past studies investigating the potential impact of HIV on cognitive functioning among children living with HIV in low-resourced settings $(2,20,60)$, and indicate a considerable burden especially in areas where there is scant provision for such difficulties. However, objective memory - assessed using an adapted item of the WISC-IV cognitive assessment tool - did not significantly vary by HIV status. This could be partly due to participant's exposure to low quality education (61), similar levels of poverty and adverse living conditions (62-66), and similar psychopathology in both groups, all of which are known to shape child development and cognitive functioning in a range of settings.

Overall, living with HIV was associated with a higher likelihood of cognitive and functional difficulties and a lower likelihood of being in an age-appropriate grade. Cognitive and functional difficulties were associated with a higher likelihood of lifetime grade repetition, and repeating multiple grades, independent of sociodemographic and household factors, and HIV status. In this setting, children are often held back a year if their performance does not meet the learning requirements. Such measures may be in the adolescent's interest and may enhance school performance in the long term, but they may also have long-term impact on school completion rates and future employability. 
When examined, the relationship between HIV status and cognitive and functional difficulties appeared to be moderated by sex in our study. Adolescent boys living with HIV were more likely to screen positive for cognitive difficulties than uninfected boys whereas the adjusted predicted probability of difficulties did not significantly differ between adolescent girls living with HIV and uninfected girls, suggesting the potential for synergistic interaction. We do not fully understand the mechanisms by which biological sex interacts with HIV to confer risk or protection against cognitive and functional difficulties. However, it is well established that younger boys have more psychopathology than younger girls and tend to perform poorer at school in younger years. In our study, girls were more likely to be in an age-appropriate grade than boys, both in the whole sample and among ALHIV respectively. They also had a lower likelihood of lifetime grade repetition, and were less likely to repeat many grades.

To the best of our knowledge, this is the first study to test associations of psychosocial factors i.e. mental health issues (depression, PTSD, suicidality and substance abuse) and HIV-related internalised stigma with cognitive and functional difficulties among ALHIV in Sub-Saharan Africa. Most African studies have focused on the effect of HIV on the mental health outcomes of youth living with HIV. Of the psychosocial factors tested here, only higher depressive symptoms remained independently associated with cognitive and functional difficulties among both ALHIV and community controls. These findings are concordant with those among perinatally HIV-infected youth in high-incomecountries $(13,67)$. The biological mechanisms underpinning the link between depression and cognitive functioning are not clearly understood. It has been suggested that depression and cognitive functioning may share common biological pathways and therefore may be reciprocally associated but findings in the current literature are equivocal. Some studies have found a bidirectional relationship whereas others did not $(68,69)$. Additionally, higher depressive symptoms predict suicidal thoughts and subsequent suicide in the general population $(70,71)$. In our study, depression and suicidality were significantly correlated (results not presented), and when depression was added to the regression model, the relationship between suicidality and cognitive difficulties was substantially attenuated and non-significant, suggesting that interventions to reduce depression may improve cognitive and physical functioning of ALHIV and their overall quality of life.

Adolescent-reported concurrent infections (past 6-months) persisted as correlates of cognitive and functional difficulties in multivariate analyses suggesting that treating chronic coinfections may resolve some of the cognitive problems experienced by adolescents in the study setting. HIV-related opportunistic infections are an indicator of disease severity. Measures of disease severity have been associated with worse cognitive impairment in past studies of HIV-positive youth (67). More often missing school for clinic appointments was associated with higher odds of cognitive and functional difficulties. Innovative approaches aimed at reducing clinic waiting times such as fast-tracked clinic queues for young people (34) and long-acting medicines that reduce the need to make frequent visits to the clinic for refills may be particularly helpful.

\section{Limitations}

Our findings should be interpreted with caution. Firstly, cross-sectional associations do not imply causation. Secondly, our proposed screening algorithm heavily relied on subjective measures and may not capture HIV-related neuronal damage. Although this may be a problem, the algorithm discriminated between potentially cognitively-affected adolescents and those who were not. Thirdly, we did not test the impact of combination ART regimens, viral load and CD4 count on cognitive and functional difficulties owing to high levels of missing ART data in patient files - common to resource-constrained healthcare systems. Fourthly, our findings may have suffered from residual confounding from unknown or known unmeasured markers of cognitive impairment such as markers of ongoing inflammation e.g. tumour necrosis factor alpha (TNF-a) and interferon-alpha (IFN-a), nadir CD4 count (lowest CD4 count before ART initiation), and cardiometabolic consequences of HIV and/or its treatment. These factors have been associated with 
cognitive impairment but were not assessed in our study because they are not routinely measured in the study setting. Nonetheless, we included a large number of theory-driven variables to control for the effects of a non-randomised design. Lastly, community controls did not have a biological HIV test and although highly unlikely, we may have included some adolescents with HIV in this group.

\section{Conclusion And Future Recommendations}

The absence of an efficient and effective screening strategy has been a major limitation for cognitive screening in lowresourced settings (17). A screening algorithm that combines results from self-reported cognitive and functional measures and a rapid objective cognitive test may be an economically-viable option for clinical practice. It may be feasible for identifying ALHIV at high risk of cognitive impairment and in need of further examination in low-andmiddle-income settings where the skill and resources required for administering comprehensive neuropsychological testing batteries are seldom available. The paediatric HIV response may benefit from integrating cognitive and mental health interventions within the HIV cascade of care to improve patient outcomes and wellbeing, and help ALHIV reach their full potential. Further studies should validate the effectiveness of a screening tool - such as the algorithm tested in this study - against neuropsychological testing batteries as the gold standard for diagnosis.

\section{Declarations}

\section{Ethics approval and consent to participate}

Ethical approvals were obtained from Universities of Oxford (SSD/CUREC2/12-21), Cape Town (CSSR 2013/14), provincial department of Basic Education (04/04/2014) and Health (29/08/2013), and participating facilities. Informed voluntary written consent was obtained from both adolescents and caregivers (when adolescents were $<18$ years old). Adolescents could withdraw from the research at any time. Linkages to healthcare and psychosocial services were provided for adolescents reporting any severe risk of harm, including defaulting from ART, symptomatic untreated TB, mental health issues such as suicidality or severe depression, and need to access special schools due to cognitive issues of the comparison group. All adolescents received a participation certificate and small pack of snacks and toiletries, regardless of whether they consented or completed their interviews.

\section{Consent for publication}

Not applicable, as this manuscript only uses quantitative data from surveys

which use unique identifiers and not names nor contact information.

\section{Availability of data and materials}

A fully anonymised version of the data used for the analyses presented in this manuscript will be made available for non-commercial use from the corresponding author on request and in accordance with the project data management policy outlined at http://www.mzantsiwakho.org.za/wpcontent/uploads/2016/05/MW_DataSharingAccessPolicy_final.pdf.

\section{Competing interests}

The authors declare no potential competing interests.

\section{Funding}


This study was supported by the Claude Leon Foundation [F08 559/C]; Evidence for HIV Prevention in Southern Africa (EHPSA), a UK aid programme managed by Mott MacDonald; the Regional Inter-Agency Task Team for Children Affected by AIDS - Eastern and Southern Africa (RIATT-ESA); the John Fell Fund [103/757]; the Leverhulme Trust; UNFPA South Africa; Oak Foundation [OFIL-20-057]. Study sponsors were not involved in study design, data collection, analyses nor interpretation, the writing of this manuscript, nor the decision to submission of this manuscript. Authors declare that they have no competing interests. The project has been funded by the Nuffield Foundation, but the views expressed are those of the authors and not necessarily the Foundation. Visit www.nuffieldfoundation.org. Fieldwork and analyses was also supported by Janssen Pharmaceutica N.V., part of the Janssen Pharmaceutical Companies of Johnson \& Johnson; the International AIDS Society through the CIPHER grant [155-Hod; 2018/625-TOS]. The views expressed in written materials or publications do not necessarily reflect the official policies of the International AIDS society. LS, LC and ET are also supported by the UKRI GCRF Accelerating Achievement for Africa's Adolescents (Accelerate) Hub (Grant Ref: ES/S008101/1).

LC is also supported by the John Fell Fund [161/033]; the South African National Department of Social Development [27/2011/11 HIV AND AIDS]; the European Research Council (ERC) under the European Union's Horizon 2020 research and innovation programme (grant agreement No 771468); the European Research Council (ERC) under the European Union's Seventh Framework Programme [FP7/2007-2013]/ ERC grant agreement n`313421; University of Oxford's ESRC Impact Acceleration Account (IAA) [K1311-KEA-004 ]. LC and ET are supported by UNICEF Eastern and Southern Africa Office (UNICEF-ESARO).

ET received support from the Fogarty International Center, National Institute on Mental Health, National Institutes of Health under Award Number K43TW011434. The content is solely the responsibility of the authors and does not represent the official views of the National Institutes of Health. Further funding was provided by Oxford University Clarendon-Green Templeton College Scholarship. MB is supported by the National Health and Medical Research Council, Australia (Investigator Grant 1173043). SN receives funding from the UK MRC (Newton fund) but the content of this paper is the responsibility of the authors and does not reflect the views of the UK Medical Research Council. All funders did not influence and were not involved with study design, data collection, analyses or interpretation of findings. Neither were they involved with the writing nor the decision to publish this manuscript. The views expressed are those of the authors and not necessarily those of the funding organisations.

\section{Author contributions}

ET and LC designed, implemented and supervised the collection, merging, cleaning and sharing of data from the larger quantitative study. $\mathrm{HN}$ conceptualised and conducted the analyses in this study, and wrote the first draft of the manuscript. LS, ET, MB and LC helped with the interpretation of findings and edited the manuscript. JH and SN reviewed the clinical relevance of the study and its findings. All authors provided a comprehensive review of the manuscript content and approved the final submission.

\section{Acknowledgements}

We thank our study participants and their caregivers for taking part in the study and sharing their lived experiences. We are grateful to partner organisations - Paediatric Adolescent Treatment for Africa \& Keiskamma Trust, participating hospitals and the field work team for their commitment towards this research.

\section{References}


1. Cohen S, Ter Stege JA, Geurtsen GJ, Scherpbier HJ, Kuijpers TW, Reiss P, et al. Poorer cognitive performance in perinatally HIV-infected children versus healthy socioeconomically matched controls. Clin Infect Dis. 2015;60(7):1111-1119. https://doi.org/10.1093/cid/ciu1144

2. Hoare J, Phillips N, Joska JA, Paul R, Donald KA, Stein DJ, et al. Applying the HIV-associated neurocognitive disorder diagnostic criteria to HIV-infected youth. Neurology. 2016;87(1):86-93.

https://doi.org/10.1212/WNL.0000000000002669

3. Bangirana P, Seggane-Musisi, Allebeck P, Giordani B, Cc J, Or O, et al. A preliminary examination of the construct validity of the KABC-II in Ugandan children with a history of cerebral malaria. Afr Health Sci. 2009;9(93):186-192. Available from: https://www.ncbi.nlm.nih.gov/pmc/articles/PMC2887024/pdf/AFHS0903-0186.pdf

4. Nozyce ML, Huo Y, Williams PL, Kapetanovic S, Hazra R, Nichols S, et al. Safety of In Utero and Neonatal ARV Exposure: Cognitive and Academic Outcomes in HIV-exposed, Uninfected Children Age 5-13 Years Support. Pediatr Infect Dis J. 2014;33(11):1128-1233. doi: 10.1097/INF.0000000000000410

5. Debeaudrap P, Bodeau-Livinec F, Pasquier E, Germanaud D, Ndiang ST, Nlend AN, et al. Neurodevelopmental outcomes in HIV-infected and uninfected African children. AIDS. 2018;32(18):2749-2757. doi: 10.1097/QAD.0000000000002023

6. Phillips N, Amos T, Kuo C, Hoare J, Ipser J, Thomas KGF, et al. HIV-Associated Cognitive Impairment in Perinatally Infected Children: A Meta-analysis. Pediatrics. 2016;38(5):1-11. https://doi.org/10.1542/peds.2016-0893

7. Ezeamama AE, Kizza FN, Zalwango SK, Nkwata AK, Zhang M, Rivera ML, et al. Perinatal HIV Status and Executive Function During School-Age and Adolescence: A Comparative Study of Long-Term Cognitive Capacity Among Children From a High HIV Prevalence Setting. Medicine. 2016;95(17):e3438. DOI: 10.1097/MD.0000000000003438

8. Hattab S, Guiguet M, Carcelain G, Fourati S, Guihot A, Autran B, et al. Soluble biomarkers of immune activation and inflammation in HIV infection: impact of 2 years of effective first-line combination antiretroviral therapy. HIV Med. 2015;16(9):553-562. https://doi.org/10.1111/hiv.12257

9. Clifford DB, Ances BM. HIV-associated neurocognitive disorder. The Lancet Infectious Diseases. 2013;13(11):976986. https://doi.org/10.1016/S1473-3099(13)70269-X

10. Iloh KK, Emodi IJ, Ibeziako NS, Ikefuna AN, Ubesie AC, Iloh ON, et al. Neurocognitive Function of School-aged HIVinfected Children in Enugu, Nigeria. J Trop Pediatr. 2017;63(6):425-430. https://doi.org/10.1093/tropej/fmx006

11. Jäncke L. Sex/gender differences in cognition, neurophysiology, and neuroanatomy. Vol. 7, F1000Research. F1000 Research Ltd; 2018. p. 1397. doi:10.12688/f1000research.13917.11

12. Sherr L, Cluver LD, Toska E, He E. Differing psychological vulnerabilities among behaviourally and perinatally HIV infected adolescents in South Africa-implications for targeted health service provision*. AIDS Care - Psychol Socio-Medical Asp AIDS/HIV. 2018;30(sup2):92-101. doi:10.1080/09540121.2018.1476664

13. Judd A, Le Prevost M, Melvin D, Arenas-Pinto A, Parrott F, Winston A, et al. Cognitive Function in Young Persons With and Without Perinatal HIV in the AALPHI Cohort in England: Role of Non-HIV-Related Factors. Clin Infect Dis. 2016;63(10):1380-1387. https://doi.org/10.1093/cid/ciw568

14. Gorman AA, Foley JM, Ettenhofer ML, Hinkin CH, Geffen D, Van Gorp WG. Functional Consequences of HIVAssociated Neuropsychological Impairment. Neuropsychol Rev. 2009;19(2):186-203. doi:10.1007/s11065-0099095-0.

15. Lawler K, Mosepele M, Ratcliffe S, Seloilwe E, Steele K, Nthobatsang R, et al. Neurocognitive impairment among HIV-positive individuals in Botswana: a pilot study. J Int AIDS Soc. 2010;13:15. doi: 10.1186/1758-2652-13-15 
16. Sirois PA, Chernoff MC, Malee KM, Garvie PA, Harris LL, Williams PL, et al. Associations of Memory and Executive Functioning With Academic and Adaptive Functioning Among Youth With Perinatal HIV Exposure and/or Infection. J Pediatric Infect Dis Soc. 2016;5(1):S24-S32. doi: 10.1093/jpids/piw046

17. Sherr L, Croome N, Parra Castaneda K, Bradshaw K, Herrero Romero R. Developmental challenges in HIV infected children-An updated systematic review. Child Youth Serv Rev. 2014;45:74-89.

18. Strehlau R, Van Aswegen T, Potterton J. Interventions Addressing Neurodevelopmental Delay in Young Children Infected with and Exposed to HIV: A Scoping Review. Vol. 37, Rehabilitation Oncology. Lippincott Williams and Wilkins; 2019. p. 7-16

19. Weber V, Radeloff D, Reimers B, Salzmann-Manrique E, Bader P, Schwabe D, et al. Neurocognitive development in HIV-positive children is correlated with plasma viral loads in early childhood. Medicine. 2017;96(23):1-6. doi: 10.1097/MD.0000000000006867

20. Ruel TD, Boivin MJ, Boal HE, Bangirana P, Charlebois E, Havlir D V., et al. Neurocognitive and Motor Deficits in HIVInfected Ugandan Children With High CD4 Cell Counts. Clin Infect Dis An Off Publ Infect Dis Soc Am. 2012;54(7):1001. https://doi.org/10.1093/cid/cir1037

21. Martin SC, Wolters PL, Toledo-Tamula MA, Zeichner SL, Hazra R, Civitello L. Cognitive Functioning in School-Aged Children With Vertically Acquired HIV Infection Being Treated With Highly Active Antiretroviral Therapy (HAART). Dev Neuropsychol. 2006;30(2):633-657. https://doi.org/10.1207/s15326942dn3002_1

22. Kandawasvika GQ, Kuona P, Chandiwana P, Masanganise M, Gumbo FZ, Mapingure MP, et al. The burden and predictors of cognitive impairment among 6- to 8-year-old children infected and uninfected with HIV from Harare, Zimbabwe: A cross-sectional study. Child Neuropsychol. 2015;21(1):106-120. https://doi.org/10.1080/09297049.2013.876493

23. Cluver L, Gardner F, Operario D. Psychological distress amongst AIDS-orphaned children in urban South Africa. J Child Psychol Psychiatry. 2007;48(8):755-763. https://doi.org/10.1111/j.1469-7610.2007.01757.x

24. Skeen S, Macedo A, Tomlinson M, Hensels IS, Sherr L. Exposure to violence and psychological well-being over time in children affected by HIV/AIDS in South Africa and Malawi. AIDS Care. 2016;28(sup1):16-25. https://doi.org/10.1080/09540121.2016.1146219

25. Mutumba M, Bauermeister JA, Harper GW, Musiime V, Lepkowski J, Resnicow K, et al. Psychological distress among Ugandan adolescents living with HIV: Examining stressors and the buffering role of general and religious coping strategies. Glob Public Health. 2017;12(12):1479-1491. Available from: https://www.tandfonline.com/doi/full/10.1080/17441692.2016.1170871

26. Meinck F, Cluver LD, Boyes ME, Loening-Voysey H. Physical, emotional and sexual adolescent abuse victimisation in South Africa: prevalence, incidence, perpetrators and locations. J Epidemiol Community Health. 2016;70(9):910-916. http://dx.doi.org/10.1136/jech-2015-205860

27. Mpango RS, Kinyanda E, Zari Rukundo G, Levin J, Gadow KD, Patel V. Prevalence and correlates for ADHD and relation with social and academic functioning among children and adolescents with HIV/AIDS in Uganda. BMC Psychiatry. 2017;17(1):336. https://doi.org/10.1186/s12888-017-1488-7

28. Kinyanda E, Kizza R, Abbo C, Ndyanabangi S, Levin J. Prevalence and risk factors of depression in childhood and adolescence as seen in 4 districts of north-eastern Uganda. BMC Int Health Hum Rights. 2013;13(19):1-10. https://doi.org/10.1186/1472-698X-13-19

29. Brailean A, Aartsen MJ, Muniz-Terrera G, Prince M, Prina AM, Comijs HC, et al. Longitudinal associations between late-life depression dimensions and cognitive functioning: a cross-domain latent growth curve analysis. Psychol Assess. 2017;47:690-702. https://doi.org/10.1017/S003329171600297X 
30. Lowe PA, Mayfield JW, Reynolds CR. Gender differences in memory test performance among children and adolescents. Arch Clin Neuropsychol. 2003;18(8):865-878.

31. Hill AC, Laird AR, Robinson JL. Gender differences in working memory networks: A BrainMap meta-analysis. Biol Psychol. 2014;102:18-29.

32. Garrido JMF, Fernandez ML, Foltz M, Castro YR, Fernandez MVC. Cognitive Performance in Men and Women Infected with HIV-1. Psychiatry J. 2013;382126. doi:10.1155/2013/382126

33. Burlacu R, Umlauf A, Luca A, Gianella S, Radoi R, Ruta SM, et al. Sex based differences in neurocognitive functioning in HIV infected young adults. AIDS. 2018;32(2):217-225.

34. Toska E, Cluver L, Orkin M, Bains A, Sherr L, Berezin M, et al. Screening and supporting through schools: educational experiences and needs of adolescents living with HIV in a South African cohort. BMC Public Health. 2019;19(272):1-10. https://doi.org/10.1186/s12889-019-6580-0

35. Lopman BA, Barnabas R V, Boerma JT, Chawira G, Gaitskell K, Harrop T, et al. Creating and validating an algorithm to measure AIDS mortality in the adult population using verbal autopsy. PLoS Med. 2006;3(8):1273-1281. https://doi.org/10.1371/journal.pmed.0030312

36. Ferrand RA, Weiss HA, Nathoo K, Ndhlovu CE, Mungofa S, Munyati S, et al. A primary care level algorithm for identifying HIV-infected adolescents in populations at high risk through mother-to-child transmission. Trop Med Int Heal. 2011;16(3):349-355. https://doi.org/10.1111/j.1365-3156.2010.02708.x

37. Cluver LD, Toska E, Orkin M, Meinck F, Hodes R, Yakubovich A, et al. Achieving equity in HIV-treatment outcomes: can social protection improve adolescent ART-adherence in South Africa? AIDS Care. 2016;28(S2):1-10. http://doi.org/10.1080/09540121.2016.1179008

38. Toska E, Cluver LD, Boyes ME, Isaacsohn M, Hodes R, Sherr L. School, Supervision and Adolescent-Sensitive Clinic Care: Combination Social Protection and Reduced Unprotected Sex Among HIV-Positive Adolescents in South Africa. AIDS Behav. 2017;21(9):2746-2759. https://doi.org/10.1007/s10461-016-1539-y

39. Natukunda HPM, Cluver LD, Toska E, Musiime V, Yakubovich AR. Beyond clinical trials: Cross-sectional associations of combination antiretroviral therapy with reports of multiple symptoms and non-adherence among adolescents in South Africa. South African Med J. 2017;107(11):965-975.

DOI:10.7196/SAMJ.2017.v107i11.12405

40. Loeb M, Cappa C, Crialesi R, Palma E de. Measuring child functioning: the Unicef/ Washington Group Module. Nota Espec. 2017;59(4):485-487. https://data.unicef.org/wp-content/uploads/2017/10/Measuring-childfunctioning.pdf

41. Goodman R. Xhosa version of the Strengths and Difficulties Questionnaire (Child report and Parent report). London Inst Psychiatry. 2004

42. Sharp C, Venta A, Marais L, Skinner D, Lenka M, Serekoane J. First evaluation of a population-based screen to detect emotional-behavior disorders in orphaned children in Sub-Saharan Africa. AIDS Behav. 2014;18(6):11741185. doi:10.1007/s10461-014-0739-6

43. Casale M, Cluver L, Crankshaw T, Kuo C, Lachman JM, Wild LG. Direct and Indirect Effects of Caregiver Social Support on Adolescent Psychological Outcomes in Two South African AIDS-Affected Communities. Am J Community Psychol. 2015;55(3-4):336-346. doi:10.1007/s10464-015-9705-3

44. Gomez R, Vance A, Watson SD. Structure of the Wechsler Intelligence Scale for Children - Fourth Edition in a Group of Children with ADHD. Front Psychol. 2016;7:737. https://doi.org/10.3389/fpsyg.2016.00737

45. Van Der Merwe A. A comparison of WISC-IV test performance for Afrikaans, English and Xhosa speaking South African Grade 7 learners. Psychology.2016 
46. Suliman Sharaian. Assessing post-traumatic responses among South African adolescents: A comparison of different methods. University of Cape Town; 2002.

https://open.uct.ac.za/bitstream/handle/11427/6958/thesis_hum_2002_suliman_s.pdf?

sequence $=1$ \&isAllowed $=y$

47. Frank-Schultz F, Naidoo P, Cloete KJ, Seedat S. The Child Posttraumatic Stress Disorder Checklist in a Sample of South African Youth. J Nerv Ment Dis. 2012;200(8):692-698

48. Boyes ME, Cluver LD, Gardner F. Psychometric properties of the child PTSD checklist in a community sample of South African children and adolescents. PLoS One. 2012;7(10):e46905.

https://doi.org/10.1371/journal.pone.0046905

49. Sheehan D, Shytle D, Milo K. MINI KID: Mini International Neuropsychiatric Interview for Children and Adolescents. English Version 40. 2004

50. Jaspan HB, Mueller AD, Myer L, Bekker L-G, Orrell C. Effect of Caregivers' Depression and Alcohol Use on Child Antiretroviral Adherence in South Africa. AIDS Patient Care STDS. 2011;25(10):595-600. Available from: https://doi.org/10.1089/apc.2010.0323

51. Pantelic M, Boyes M, Cluver L, Thabeng M. 'They Say HIV is a Punishment from God or from Ancestors': CrossCultural Adaptation and Psychometric Assessment of an HIV Stigma Scale for South African Adolescents Living with HIV (ALHIV-SS). Child Indic Res. 2018;11(1):207-223. https://doi.org/10.1007/s12187-016-9428-5

52. Mathews C, Eggers SM, Townsend L, Aarø LE, de Vries PJ, Mason-Jones AJ, et al. Effects of PREPARE, a Multicomponent, School-Based HIV and Intimate Partner Violence (IPV) Prevention Programme on Adolescent Sexual Risk Behaviour and IPV: Cluster Randomised Controlled Trial. AIDS Behav. 2016;20(9):1821-1840. doi:10.1007/s10461-016-1410-1

53. Graham SM, Ahmed T, Amanullah F, Browning R, Cardenas V, Casenghi M, et al. Evaluation of tuberculosis diagnostics in children: 1. Proposed clinical case definitions for classification of intrathoracic tuberculosis disease. Consensus from an expert panel. J Infect Dis. 2012;205(Suppl 2):S199-S208.

https://doi.org/10.1093/infdis/jis008

54. DPHHS. Montana DPHHS-Tuberculosis Program Tuberculosis Symptom Assessment. https://dphhs.mt.gov/Portals/85/publichealth/documents/CDEpi/DiseasesAtoZ/TB/TBSymptomAssessment.pdf

55. Ferrand RA, Corbett EL, Wood R, Hargrove J, Ndhlovu CE, Cowan FM, et al. AIDS among older children and adolescents in Southern Africa: projecting the time course and magnitude of the epidemic. AIDS.

2009;23(15):2039-2046. https:// doi.org/10.1097/QAD.0b013e32833016ce

56. Paterson DL, Swindells S, Mohr J, Brester M, Vergis EN, Squier C, et al. Adherence to Protease Inhibitor Therapy and Outcomes in Patients with HIV Infection. Ann Intern Med. 2000;133(1):21-30. https://doi.org/10.7326/00034819-133-1-200007040-00004

57. Duong M, Piroth L, Grappin M, Forte F, Peytavin G, Buisson M, et al. Evaluation of the Patient Medication Adherence Questionnaire as a tool for self-reported adherence assessment in HIV-infected patients on antiretroviral regimens. HIV Clin Trials. 2015;2(2):128-135. https://doi.org/10.1310/M3JR-G390-LXCM-F62G

58. Lowenthal ED, Jibril HB, Sechele ML, Mathuba K, Tshume O, Anabwani GM. Disclosure of HIV status to HIVinfected children in a large African treatment center: Lessons learned in Botswana. Child Youth Serv Rev. 2014;45:143-149. https:// doi.org/10.1016/j.childyouth.2014.03.031

59. Pillay U, Roberts B, Rule S. South African Social Attitudes Changing TImes, Diverse Voices. Pillay U, Roberts B, Rule S, editors. 2006. 1-391 p. Available from: http://www.hsrc.ac.za/en/departments/sasas/sasas-related-books

60. Puthanakit T, Aurpibul L, Louthrenoo O, Tapanya P, Nadsasarn R, Insee-ard S, et al. Poor cognitive functioning of school-aged children in thailand with perinatally acquired HIV infection taking antiretroviral therapy. AIDS Patient

Page $15 / 23$ 
Care STDS. 2010;24(3):141-146. doi:10.1089/apc.2009.0314

61. Shuttleworth-Edwards AB, van der Merwe AS, van Tonder P, Radloff SE. WISC-IV test performance in the South African context: In: Psychological Assessment in South Africa. Wits University Press; 2018. p. 33-47.

62. Dean EB, Schilbach F, Schofield H, Dean EB, Schilbach F, Schofield H. Poverty and Cognitive Function. In: The Economics of Poverty Traps. National Bureau of Economic Research, Inc; 2017. p. 57-118. https://econpapers.repec.org/RePEc:nbr:nberch:13830

63. Cermakova P, Formanek T, Kagstrom A, Winkler P. Socioeconomic position in childhood and cognitive aging in Europe. Neurology. 2018;91(17):E1602-1610. https://doi.org/10.1212/WNL.0000000000006390

64. Schoon I, Jones E, Cheng H, Maughan B. Family hardship, family instability, and cognitive development. J Epidemiol Community Health. 2012;66(8):716-722. http://dx.doi.org/10.1136/jech.2010.121228

65. Haft SL, Hoeft F. Poverty's Impact on Children's Executive Functions: Global Considerations. Vol. 2017, New Directions for Child and Adolescent Development. Wiley-Blackwell Publishing; 2017. p. 69-79. doi:10.1002/cad.20220

66. Blair C, Raver CC. Poverty, Stress, and Brain Development: New Directions for Prevention and Intervention. Vol. 16, Academic Pediatrics. Elsevier Inc.; 2016. p. S30-S36. doi:10.1016/j.acap.2016.01.010

67. Nachman S, Chernoff M, Williams P, Hodge J, Heston J, Gadow KD. Human immunodeficiency virus disease severity, psychiatric symptoms, and functional outcomes in perinatally infected youth. Arch Pediatr Adolesc Med. 2012;166(6):528-535. https://doi:10.1001/archpediatrics.2011.1785

68. Halahakoon DC, Lewis G, Roiser JP. Cognitive Impairment and Depression-Cause, Consequence, or Coincidence? JAMA Psychiatry. 2019];76(3):239. doi:10.1001/jamapsychiatry.2018.3631

69. Perrino T, Mason CA, Brown SC, Spokane A, Szapocznik J. Longitudinal Relationships Between Cognitive Functioning and Depressive Symptoms Among Hispanic Older Adults. Journals Gerontol Ser B Psychol Sci Soc Sci. 2008;63(5):P309-317. https://doi.org/10.1093/geronb/63.5.P309

70. Strandheim A, Bjerkeset O, Gunnell D, Bjørnelv S, Lingaas Holmen T, Bentzen N. Risk factors for suicidal thoughts in adolescence-a prospective cohort study: the Young-HUNT study. Open. 2014;4:5867. http://dx.doi.org/10.1136/bmjopen-2014-005867

71. Takeuchi T, Nakao M. The relationship between suicidal ideation and symptoms of depression in Japanese workers: a cross-sectional study. BMJ Open. 2013;3(11):e003643. http://dx.doi.org/10.1136/bmjopen-2013003643

\section{Tables}

Table 1: Characteristics of adolescents in the study sample disaggregated by HIV status $(n=1526)$ 


\begin{tabular}{|c|c|c|c|c|}
\hline & $\begin{array}{l}\text { All } \\
\text { adolescents } \\
(n=1526)\end{array}$ & $\begin{array}{l}\text { Adolescents living with HIV } \\
(n=1059)\end{array}$ & $\begin{array}{l}\text { Community } \\
\text { Controls } \\
(n=467)\end{array}$ & $\begin{array}{l}\mathrm{X}^{2} \text { or } \mathrm{t}- \\
\text { statistic }\end{array}$ \\
\hline Measures & $\begin{array}{l}\mathrm{n}(\%) \text { or } \\
\text { mean (SD) }\end{array}$ & $n(\%)$ or mean (SD) & $\begin{array}{l}\mathrm{n}(\%) \text { or mean } \\
\text { (SD) }\end{array}$ & \\
\hline \multicolumn{5}{|l|}{ Sociodemographic factors } \\
\hline Age (years), median (IQR) & $14(11-17)$ & $13(11-16)$ & $15(12-17)$ & $32.05^{\star \star \star \S}$ \\
\hline Female sex & $867(56.8)$ & $583(55.1)$ & $284(60.8)$ & $4.39 *$ \\
\hline Primary school grade $(n=1437)$ & $836(54.8)$ & $632(63.5)$ & $204(46.2)$ & $37.92^{\star \star \star}$ \\
\hline Age-appropriate grade $(n=1437)$ & $711(46.6)$ & $460(46.2)$ & $251(56.8)$ & $13.64^{\star \star \star}$ \\
\hline Ever repeated a grade & $726(47.6)$ & $529(50.0)$ & $197(42.2)$ & $7.84^{\star \star}$ \\
\hline Rural residence & $337(22.2)$ & 227 (21.5) & $110(23.8)$ & 0.94 \\
\hline Informal housing & $272(17.8)$ & $199(18.8)$ & $73(15.6)$ & 2.21 \\
\hline $\begin{array}{l}\text { Orphanhood (lost at least one } \\
\text { parent) }\end{array}$ & $791(51.8)$ & $619(58.5)$ & $172(36.8)$ & $60.68^{\star \star \star}$ \\
\hline \multicolumn{5}{|l|}{ Household factors } \\
\hline $\begin{array}{l}\text { Poverty (lacking access to basic } \\
\text { needs) }\end{array}$ & $1012(66.3)$ & $715(67.5)$ & $297(63.6)$ & 2.23 \\
\hline Food insecurity & $211(13.8)$ & $153(14.5)$ & $58(12.4)$ & 1.13 \\
\hline \multicolumn{5}{|l|}{ Psychosocial factors } \\
\hline Depressive symptoms scale & $1.30(2.10)$ & $1.25(1.98)$ & $1.40(2.35)$ & 1.26 \\
\hline PTSD symptoms scale & $5.26(7.29)$ & $5.10(6.78)$ & $5.60(8.34)$ & 1.23 \\
\hline Suicidality scale & $0.21(0.81)$ & $0.19(0.78)$ & $0.25(0.88)$ & 1.29 \\
\hline Substance abuse & $70(4.6)$ & $40(3.8)$ & $30(6.4)$ & $5.17^{\star}$ \\
\hline $\begin{array}{l}\text { HIV-related internalised stigma } \\
\text { scale }\end{array}$ & $0.41(1.23)$ & $0.59(1.29)$ & - & - \\
\hline \multicolumn{5}{|l|}{ Healthcare-related factors } \\
\hline $\begin{array}{l}\text { Missing school for clinics ( } 3 \\
\text { times or more) }\end{array}$ & $407(26.7)$ & $373(35.2)$ & $34(7.3)$ & $129.37^{* \star *}$ \\
\hline${ }^{\dagger}$ Concurrent infections & $879(57.6)$ & $674(63.6)$ & $205(43.9)$ & $51.75^{\star \star \star}$ \\
\hline Vertical infection & $708(46.4)$ & 708 (66.9) & - & - \\
\hline cART duration (median) & $5(2-10)$ & $5(2-10)$ & - & - \\
\hline $\begin{array}{l}\text { Past-week medication non- } \\
\text { adherence }\end{array}$ & $385(25.2)$ & $385(36.4)$ & - & - \\
\hline Cognitive and functional outcome & & & & \\
\hline
\end{tabular}




\begin{tabular}{|lllll|}
\hline $\begin{array}{l}\text { Past 6-month cognitive difficulties } \\
\text { issues }\end{array}$ & $411(26.9)$ & $322(30.4)$ & $89(19.1)$ & $21.21^{\star \star \star}$ \\
\hline $\begin{array}{l}\text { Slow learner by caregiver/school } \\
\text { report }\end{array}$ & $3(0.2)$ & $2(0.2)$ & $31(6.6)$ & 1.10 \\
\hline $\begin{array}{l}\text { Attending a special school } \\
\text { Past 6-month functional difficulties }\end{array}$ & $38(2.5)$ & $26(2.5)$ & $1(0.2)$ & 0.01 \\
\hline $\begin{array}{l}<60 \% \text { recall on a memory word } \\
\text { task }\end{array}$ & $940(61.6)$ & $653(61.7)$ & $13(2.8)$ & 0.14 \\
\hline $\begin{array}{l}\text { ₹Cognitive and functional } \\
\text { difficulties }\end{array}$ & $295(19.3)$ & $232(21.9)$ & $74(15.9)$ & $13.81^{\star \star \star}$ \\
\hline
\end{tabular}

HIV: human immunodeficiency virus, ART: antiretroviral therapy, n: number, \%: percentage, IQR: interquartile range, SD: standard deviation, §value from median test for age, PTSD: post-traumatic stress disorder, cART: combination antiretroviral therapy, SDQ: strength and difficulties questionnaire, ${ }^{\ddagger}$ computed using the proposed algorithm (any cognitive problems plus functional problems). ${ }^{\dagger}$ Any skin rash/shingles or sores on the body or face or mouth ulcers or probable tuberculosis infection. ${ }^{* *} p<.001,{ }^{*} p<.01,{ }^{*} p<.05$

Table 2: Validation of the cognitive and functional difficulties screening algorithm with A) adolescent-reports of lifetime grade repetition

and B) lifetime number of grades repeated 


\begin{tabular}{|c|c|c|c|c|}
\hline & \multicolumn{2}{|c|}{$\begin{array}{l}\text { A: Lifetime grade } \\
\text { repetition } \\
(n=1526)^{\S}\end{array}$} & \multicolumn{2}{|c|}{$\begin{array}{l}\text { B: Lifetime number of grades repeated } \\
(n=1526)^{\S}\end{array}$} \\
\hline Measures & aOR $(95 \% \mathrm{Cl})$ & $P$-value & $\beta^{\ddagger}(\mathrm{SE})$ & $P$ value \\
\hline \multicolumn{5}{|l|}{ Sociodemographic factors } \\
\hline Age (per unit increase) & $\begin{array}{l}1.10(1.06- \\
1.14)\end{array}$ & $<.001$ & $.072(.012)$ & $<.001$ \\
\hline Female sex & $\begin{array}{l}0.62(0.50- \\
0.77)\end{array}$ & $<.001$ & $-.324(.072)$ & $<.001$ \\
\hline Rural residence & $\begin{array}{l}1.50(1.16- \\
1.94)\end{array}$ & .002 & $.215(.081)$ & .008 \\
\hline Informal housing & $\begin{array}{l}1.04(0.79- \\
1.37)\end{array}$ & .791 & $.127(.089)$ & .154 \\
\hline Orphanhood (any) & $\begin{array}{l}1.12(0.90- \\
1.38)\end{array}$ & .317 & $.110(.072)$ & .127 \\
\hline \multicolumn{5}{|l|}{ Household factors } \\
\hline $\begin{array}{l}\text { Poverty (lacking access to basic } \\
\text { needs) }\end{array}$ & $\begin{array}{l}1.19(0.95- \\
1.50)\end{array}$ & .128 & $.020(.077)$ & .795 \\
\hline Food insecurity & $\begin{array}{l}0.29(0.06- \\
1.33)\end{array}$ & .110 & $.086(.099)$ & .384 \\
\hline \multicolumn{5}{|l|}{ Healthcare-related factors } \\
\hline HIV positive status & $\begin{array}{l}1.29(1.01- \\
1.64)\end{array}$ & .042 & $.152(.084)$ & .070 \\
\hline $\begin{array}{l}\text { Missing school for clinics ( } 3 \text { times or } \\
\text { more) }\end{array}$ & $\begin{array}{l}1.28(1.00- \\
1.64)\end{array}$ & .051 & $.135(.080)$ & .093 \\
\hline \multicolumn{5}{|l|}{ Algorithm } \\
\hline Cognitive and functional difficulties & $\begin{array}{l}1.62(1.24- \\
2.11)\end{array}$ & $<.001$ & $.267(.083)$ & $<.001$ \\
\hline
\end{tabular}

§All variables were simultaneously tested, aOR = adjusted odds ratio, ‡unstandardised beta coefficient, SE: standard error, HIV: human immunodeficiency virus.

Table 3: Multivariable logistic regression of factors associated with cognitive and functional difficulties in the full sample $(n=1526)$ 


\begin{tabular}{|c|c|c|}
\hline & \multicolumn{2}{|c|}{$\begin{array}{l}\text { Outcome: cognitive and functional difficulties } \\
\text { All factors tested simultaneously ( } n=1451 \text { ) }\end{array}$} \\
\hline Measures & aOR $(95 \% \mathrm{Cl})$ & $P$ value \\
\hline \multicolumn{3}{|l|}{ Sociodemographic factors } \\
\hline Age (per unit increase) & $0.96(0.91-1.01)$ & .094 \\
\hline Female sex & $1.99(1.06-3.71)$ & .031 \\
\hline Rural residence & $1.02(0.73-1.41)$ & .920 \\
\hline Informal housing & $0.98(0.69-1.39)$ & .893 \\
\hline Orphanhood (any) & $1.14(0.87-1.51)$ & .345 \\
\hline \multicolumn{3}{|l|}{ Household factors } \\
\hline Poverty (lacking access to basic needs) & $1.00(0.75-1.35)$ & .986 \\
\hline Food insecurity & $1.31(0.90-1.91)$ & .154 \\
\hline \multicolumn{3}{|l|}{ Psychosocial factors } \\
\hline Depressive symptoms scale (per unit increase) & $1.18(1.11-1.26)$ & $<.001$ \\
\hline PTSD symptoms scale (per unit increase) & $1.00(0.99-1.02)$ & .623 \\
\hline Suicidality scale (per unit increase) & $0.97(0.82-1.15)$ & .715 \\
\hline Substance abuse (past 3-month) & $1.16(0.62-2.16)$ & .647 \\
\hline HIV-related internalised stigma scale (per unit increase) & $1.10(0.98-1.24)$ & .099 \\
\hline \multicolumn{3}{|l|}{ Healthcare-related factors } \\
\hline Missing school for clinics ( 3 times or more) & $1.66(1.24-2.23)$ & $<.001$ \\
\hline${ }^{\dagger}$ Concurrent infections & $1.92(1.44-2.58)$ & $<.001$ \\
\hline HIV status (positive) & $2.21(1.19-4.11)$ & .012 \\
\hline HIV status (positive) x sex (girl) & $0.49(0.25-0.98)$ & .044 \\
\hline §HIV status (positive) x sex (boy) & $2.04(1.02-4.07)$ & .044 \\
\hline Past-week nonadherence & $1.13(0.83-1.54)$ & .439 \\
\hline \multicolumn{3}{|l|}{ Model statistics } \\
\hline $\operatorname{LR} \operatorname{chi}^{2}(\mathrm{df})$ & $115.59(17)$ & \\
\hline Prob > chi ${ }^{2}$ & $<.0001$ & \\
\hline Pseudo R² (\%) & 7.75 & \\
\hline
\end{tabular}

aOR: adjusted odds ratio, PTSD: post-traumatic stress disorder, HIV: human immunodeficiency virus, TB: Tuberculosis.

${ }^{\dagger}$ Any skin rash/shingles or sores on the body or face or mouth ulcers or probable tuberculosis infection. §From the 
same model but with reverse-coded sex. CART duration and mode of infection were dropped from analysis due strong collinearity with age and HIV status. Significant factors are in bold face.

\section{Figures}

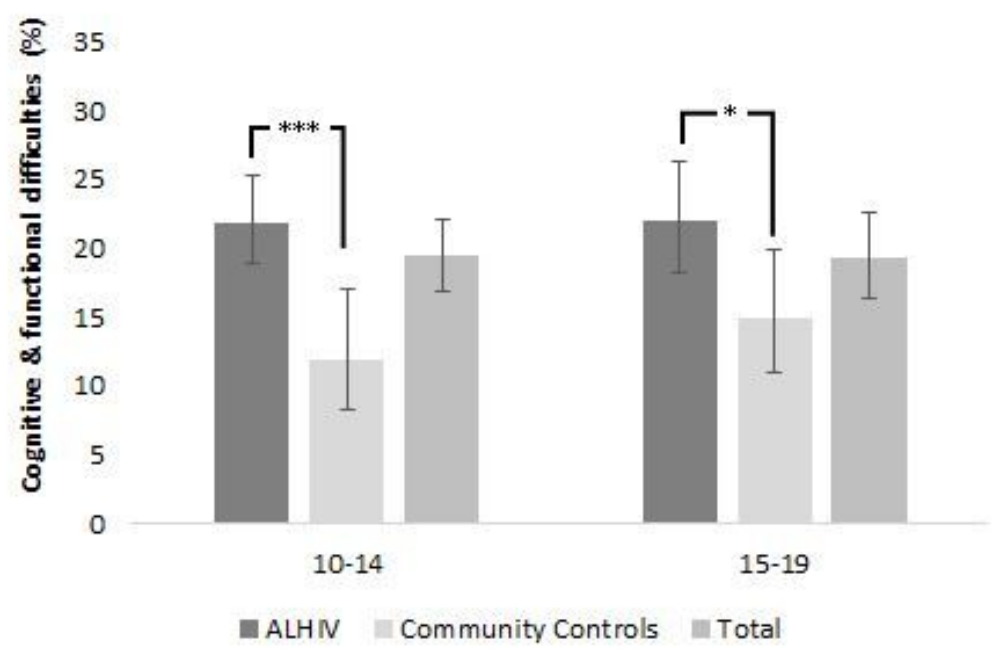

Figure 1

Prevalence of cognitive and functional difficulties by age and HIV status ***p $<.001$, ${ }^{*} p<.05$

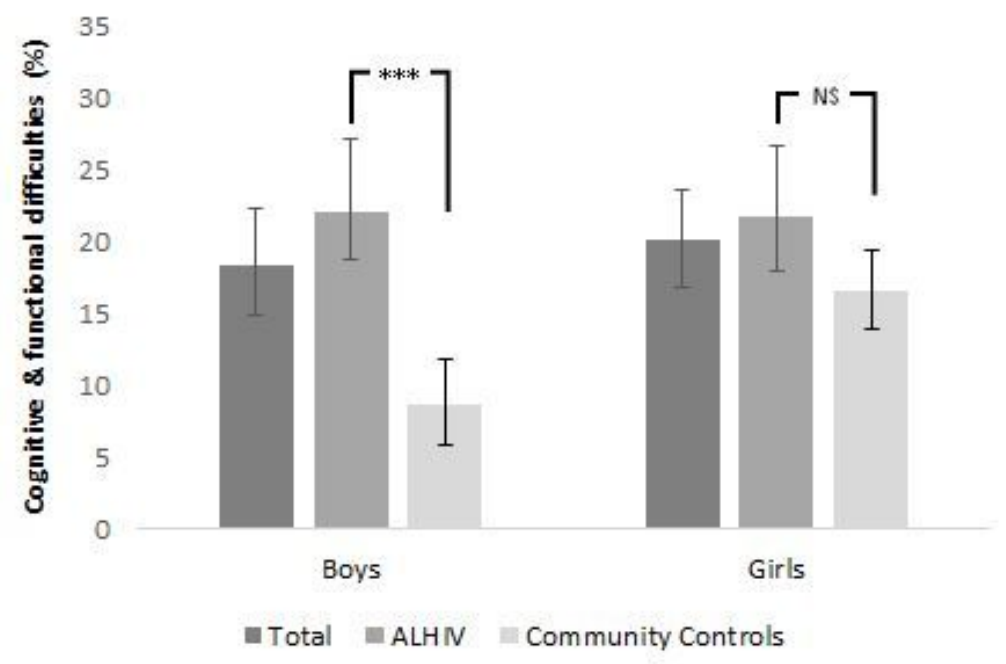

Figure 2

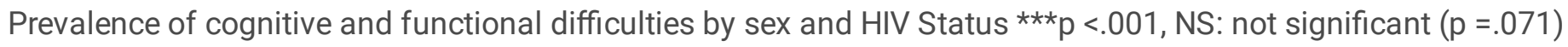




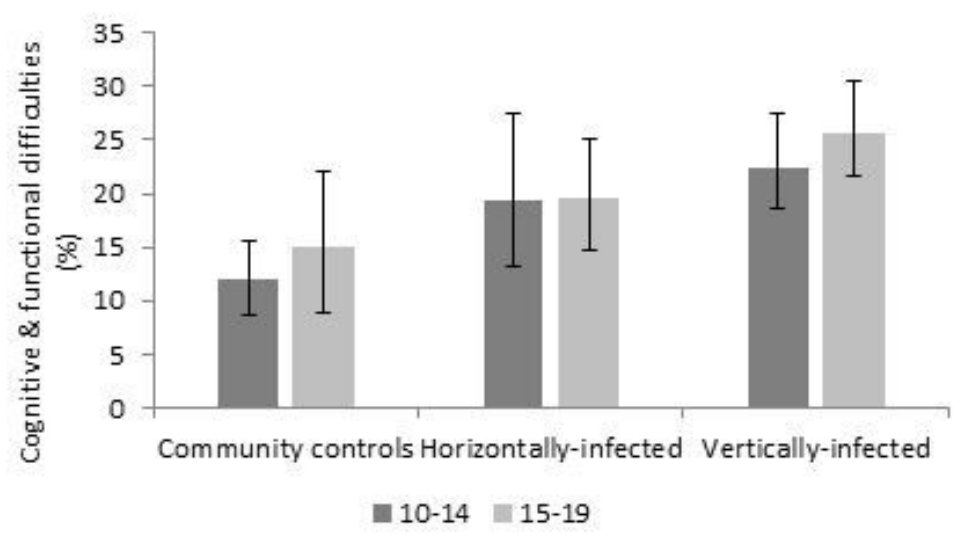

\section{Figure 3}

Prevalence of cognitive and functional difficulties by age and mode of HIV infection

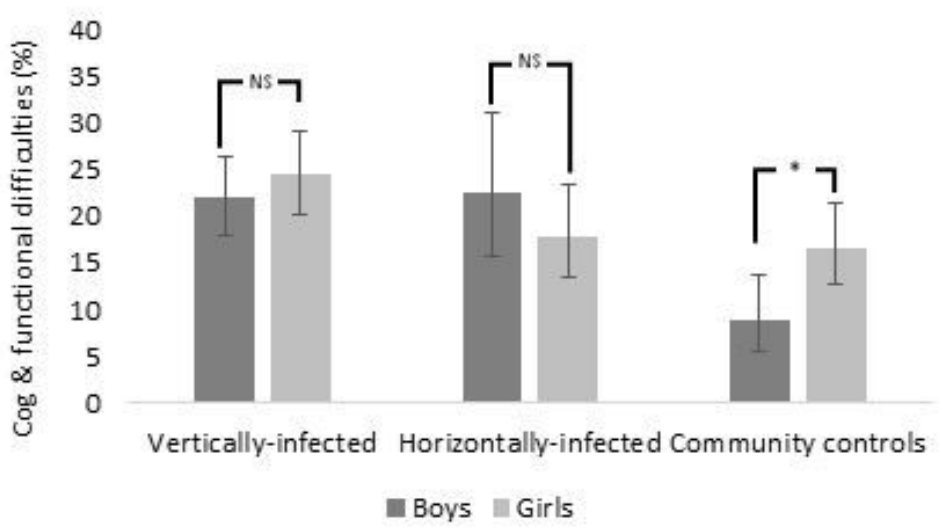

\section{Figure 4}

Prevalence of cognitive and functional difficulties by sex and mode of infection NS: not significant, *P<.05

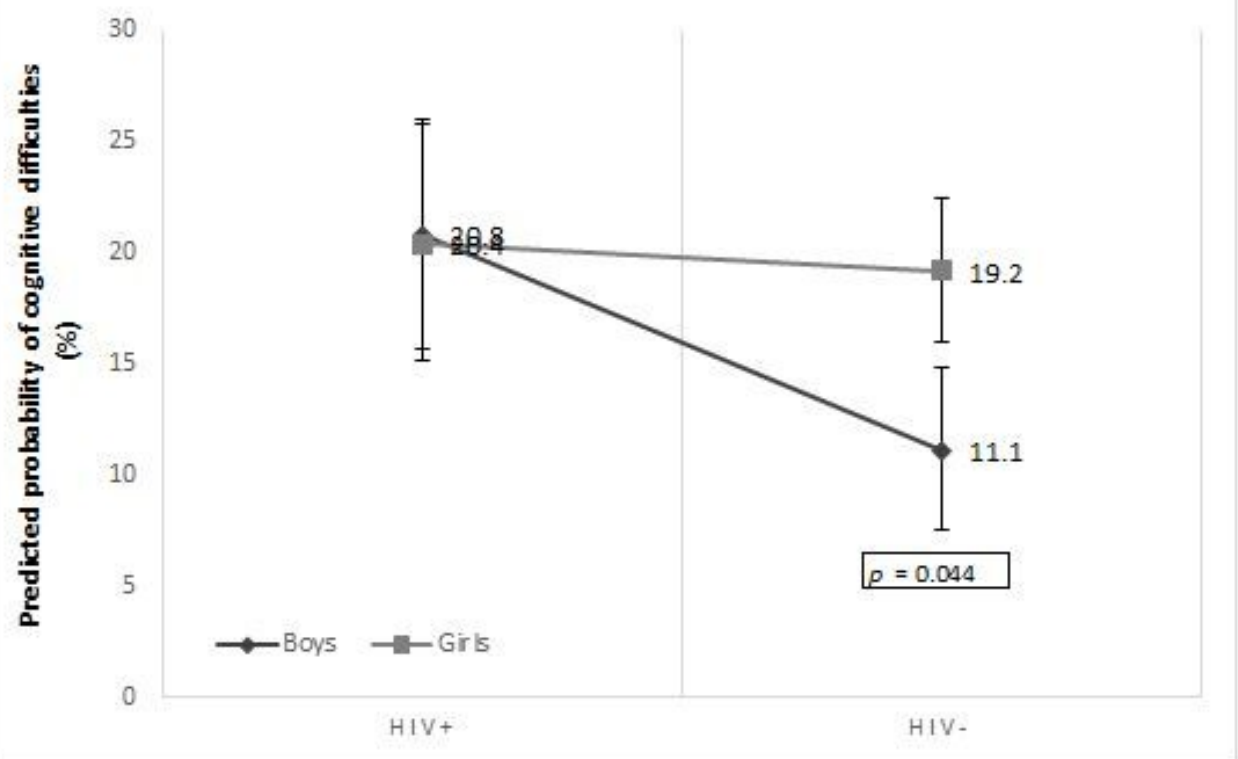


Figure 5

HIV x sex interaction effects from marginal effects modelling 